\title{
Interleukin-13 induces collagen type-1 expression through matrix metallo- proteinase-2 and transforming growth factor- $\beta 1$ in airway fibroblasts in asthma
}

\author{
Rafael Firszt ${ }^{1}$, Dave Francisco², Tony D. Church², Joseph M. Thomas², \\ Jennifer L. Ingram² and Monica Kraft ${ }^{2}$
}

\begin{abstract}
Affiliations: ${ }^{1}$ Dept of Pediatrics, Division of Allergy, Immunology and Rheumatology, University of Utah, Salt Lake City, UT, and ${ }^{2}$ Dept of Medicine, Division of Pulmonary, Allergy and Critical Care, Duke University Medical Center, Durham, NC, USA.
\end{abstract}

Correspondence: M. Kraft, Duke University Medical Center, Medical Sciences Research Building 1, Room 275 , Durham, NC, 27710, USA. E-mail: monica.kraft@duke.edu

ABSTRACT Airway remodelling is a feature of asthma that contributes to loss of lung function. One of the central components of airway remodelling is subepithelial fibrosis. Interleukin (IL)-13 is a key T-helper 2 cytokine and is believed to be the central mediator of allergic asthma including remodelling, but the mechanism driving the latter has not been elucidated in human asthma.

We hypothesised that IL-13 stimulates collagen type-1 production by the airway fibroblast in a matrix metalloproteinase (MMP)- and transforming growth factor (TGF)- $\beta 1$-dependent manner in human asthma as compared to healthy controls.

Fibroblasts were cultured from endobronchial biopsies in 14 subjects with mild asthma and 13 normal controls that underwent bronchoscopy. Airway fibroblasts were treated with various mediators including IL-13 and specific MMP-inhibitors. IL-13 significantly stimulated collagen type-1 production in asthma compared to normal controls. Inhibitors of MMP-2 significantly attenuated collagen production in asthma but had no effect in normal controls. IL-13 significantly increased total and active forms of TGF- $\beta 1$, and this activation was blocked using an MMP-2 inhibitor. IL-13 activated endogenous MMP-2 in asthma patients as compared to normal controls.

In an ex vivo model, IL-13 potentiates airway remodelling through a mechanism involving TGF- $\beta 1$ and MMP-2. These effects provide insights into the mechanism involved in IL-13-directed airway remodelling in asthma.

@ERSpublications

IL-13 potentiates collagen production in a TGF- $\beta 1$-dependent manner providing insight into airway remodelling in asthma http://ow.ly/r5v7s

This article has supplementary material available from www.erj.ersjournals.com

Received: April 302012 | Accepted after revision: May 012013 | First published online: May 162013

Support statement: This study was supported by the National Institutes of Health National Heart, Lung and Blood Institute (NIH-NHLBI HL-05-009).

Conflict of interest: Disclosures can be found alongside the online version of this article at www.erj.ersjournals.com

Copyright @ERS 2014 


\section{Introduction}

Asthma is a chronic inflammatory disease of the airways, where specific inflammatory phenotypes are dominated by T-helper (Th)2 cytokines. Interleukin (IL)-13, which is primarily produced by $\mathrm{T}$ lymphocytes, is considered to be the central mediator of allergic asthma [1]. This chronic Th2-driven inflammation causes tissue injury that is believed to cause structural changes and airway remodelling in asthma [2]. Airway remodelling contributes significantly to airway dysfunction and persistent clinical symptoms in patients with asthma [3]. Furthermore, a significant proportion of patients with severe asthma develop progressive and persistent airflow limitation over time, providing further evidence that remodelling plays a role in impairment of lung function [4]. However, the direct effects of Th2 cytokines on the remodelling process have not been extensively studied in human disease.

One of the key characteristics of airway remodelling is subepithelial fibrosis caused by deposition of extracellular collagen and other matrix components [5]. The primary collagen within the airway extracellular matrix is type-I collagen; however, type-III and type-V collagen are also major constituents of the subepithelial basement membrane [6]. This collagen is produced by fibroblasts and myofibroblasts, and the degree of fibrosis correlates with increased numbers of these cells in asthma [7].

Collagen deposition in tissues is believed to be controlled by matrix metalloproteinases (MMPs) and their corresponding tissue inhibitors of metalloproteinases (TIMPs). MMPs are a family of enzymes characterised by a common zinc ion at their active site. In general, MMPs and TIMPs are thought to be involved in the normal maintenance of extracellular matrix; however, they have also been shown to be involved in inflammation and cell-cell signalling [8]. Various cells are involved in producing the different MMPs. For example, macrophages, but not fibroblasts, produce MMP-9, whereas MMP-2 is produced by variety of cells, including fibroblasts [9]. ZHENG et al. [10] reported that MMP-2 and MMP-9 were elevated in the bronchoalveolar fluids of IL-13 transgenic mice.

Transforming growth factor (TGF)- $\beta 1$ is produced by many cells within the lung, including fibroblasts, and is a well-characterised mediator of tissue fibrosis [11]. TGF- $\beta 1$ mRNA has been shown to be increased in moderate-to-severe asthmatics, and its expression was shown to be directly related to subepithelial fibrosis [12]. Previous reports have shown that IL-13 functions through TGF- $\beta 1$ to induce a pro-fibrotic response [13-18]. Mechanisms involved in stimulating TGF- $\beta 1$ have included both an increase in latent production and/or increased activation through an MMP-dependent mechanism. In IL-13 transgenic mice, MMP-9 was shown to play an important role in activating TGF- $\beta 1$, demonstrating that MMPs may be an important link between IL-13 and TGF- $\beta 1$ [14]. In addition, IL-13-induced fibrosis was significantly reduced in MMP-9deficient mice.

Despite the evidence that IL-13 is involved in airway remodelling in murine models of asthma, its effects have yet to be demonstrated in human subjects. For the present study, we chose an ex vivo method of analysing airway fibroblasts isolated directly from well-characterised patients with asthma to test our hypothesis that IL-13 modulates collagen production by airway fibroblasts in asthma and that MMPs and TGF- $\beta 1$ are critical mediators in this process. Our findings have therapeutic implications given that IL-13 antagonists for humans are now under study for treatment of asthma.

\section{Methods}

\section{Subject recruitment}

27 research participants were recruited from the general Research Triangle (NC, USA) community. The asthmatics fulfilled criteria for asthma by exhibiting a provocative concentration of methacholine resulting in a $20 \%$ fall in the forced expiratory volume in $1 \mathrm{~s}(\mathrm{FEV} 1)$ of $<8 \mathrm{mg} \cdot \mathrm{mL}^{-1}$ and reversibility, as demonstrated by $\geqslant 12 \%$ and $\geqslant 200 \mathrm{~mL}$ increase in the $\mathrm{FEV} 1$ or forced vital capacity with inhaled albuterol [19]. All participants provided informed consent in this Duke University (Durham, NC, USA) institutional review board-approved protocol. Additional details are available in the online supplementary material.

\section{Bronchoscopy}

Subjects underwent bronchoscopy with endobronchial biopsy as previously described [20].

\section{Airway fibroblast culture}

Endobronchial tissue sections were placed on collagen-coated plates and fibroblasts were cultured as previously described [21]. As numerous passages can induce cellular metaplasia and senescence, only cells from the first three passages were used for experimentation [22]. 


\section{Mediator exposure}

When the cells were at confluence for 7 days, the medium was changed, and cells were incubated in serumfree media for $24 \mathrm{~h}$. Cells were subsequently treated with and without IL-13 (50 ng $\cdot \mathrm{mL}^{-1}$; ProSpec, Rehovot, Israel) for $48 \mathrm{~h}$. In addition, cells were treated with various MMP-inhibitors and TGF- $\beta$ receptor-II (TGF$\beta$ RII)-neutralising antibody. For detailed description see the online supplementary material.

\section{Quantitative real-time reverse transcriptase-PCR}

Total RNA from airway fibroblasts was extracted using TRIzol (Life Technologies, Grand Island, NY, USA) after exposure to mediators. Relative mRNA expression was calculated by normalisation of all expression levels to glyceraldehyde-3-phosphate dehydrogenase (GAPDH) and then compared to untreated control cells by the $\Delta \Delta \mathrm{CT}$ method [23]. See the online supplementary material for additional details.

\section{ELISA}

Supernatants from cultured airway fibroblasts were collected $48 \mathrm{~h}$ after mediator treatment in asthma and normal subjects. Measurement of collagen type-1 protein was performed by using a commercial ELISA kit according to the manufacturer's protocol (MD Bioproducts, St Paul, MN, USA). Results are reported as a ratio of IL-13-treated cells to untreated fibroblasts. Measurement of TGF- $\beta 1$ protein was performed using a commercial ELISA kit according to the manufacturer's protocol (R\&D Systems, Minneapolis, MN, USA).

\section{MMP-2 activation assay}

Supernatants from cultured airway fibroblasts were collected $48 \mathrm{~h}$ after IL-13 $\left(50 \mathrm{ng} \cdot \mathrm{mL}^{-1}\right)$ treatment in asthma and normal subjects and compared to untreated fibroblasts (baseline). Measurement of MMP-2 activity was performed by using a commercial activity assay system according to the manufacturer's protocol (GE Healthcare, Chalfont St Giles, UK). Results are reported as a ratio of IL-13-treated cells to untreated fibroblasts. For additional details, see the online supplementary material.

\section{Luciferase activity}

Supernatants from cultured airway fibroblasts were collected at $48 \mathrm{~h}$ after IL-13 $\left(50 \mathrm{ng} \cdot \mathrm{mL}^{-1}\right)$ treatment in asthma and normal subjects. Measurement of active TGF- $\beta 1$ was performed using a CCL64 mink lung epithelial cell line (generous gift from S. Mukherjee, Duke University) with a plasminogen activator inhibitor (PAI)-1 luciferase reporter system. This assay has been previously used and is sensitive and specific for TGF- $\beta[24,25]$. Luciferase activity was developed according to protocol instructions (Perkin Elmer, Waltham, MA, USA) and measured using a luminometer (BMG Labtech, Ortenberg, Germany). Results are expressed as relative luciferase units (RLU).

\section{Western blot analysis}

Cell lysates from cultured airway fibroblasts were collected at $48 \mathrm{~h}$ after IL-13 (50 $\left.\mathrm{ng} \cdot \mathrm{mL}^{-1}\right)$ treatment and probed for $\alpha$-smooth muscle actin (SMA), desmin and GAPDH. The blot was developed by enhanced chemiluminescence, documented with the Kodak Image Station 4000 MM PRO (Carestream Health Inc., Rochester, NY, USA) and quantified using Carestream Molecular Image software (version 5.0; Carestream Health Inc.). The Western blot analysis was performed in six asthma and four normal control subjects demonstrating consistent bands at the correct molecular weights to confirm reproducibility. Densitometry analysis of Western blots was performed with the use of PDI Imageware System (Carestream Health Inc.). Results are reported as ratio IL-13 treated cells to untreated fibroblasts. For additional details, see the online supplementary material.

\section{Statistical analysis}

Statistical evaluation was performed using JMP statistical software (SAS Institute, Cary, NC, USA). The mean values from each condition were determined as each condition was performed in triplicate. Data are presented as mean \pm SEM. All data were compared using a two-tailed Wilcoxon rank sum test. Significance is denoted by $\mathrm{p}<0.05$.

\section{Results}

Subjects

Subject characteristics are shown in table 1. Asthmatic subjects were mild as defined by the National Asthma Education and Prevention Program criteria [26].

\section{Collagen gene expression by airway fibroblasts}

We evaluated COL1A1, COL1A2 and COL3A1 gene expression by airway fibroblasts in subjects with asthma and healthy controls in response to various mediators. We observed similar levels of mRNA expression in 
TABLE 1 Participant characteristics

Asthma

Healthy controls

p-value

$\begin{array}{lc}\text { Subjects } & 14 \\ \text { Female/male } & 8 / 6 \\ \text { Age years } & 25 \pm 2 \\ \text { FEV } 1 \text { L } & 3.87 \pm 0.2 \\ \text { FEV } 1 \% \text { pred } & 98 \pm 4 \\ \text { FVC L } & 4.83 \pm 0.2 \\ \text { FVC \% pred } & 98 \pm 3 \\ \text { FEV } 1 \text { /FVC } & 0.80 \pm 0.02 \\ \text { PC } 20 \text { mg } \cdot \mathrm{mL}^{-1} & 0.5 \pm 0.01\end{array}$

13
$8 / 5$
$29 \pm 2$
$3.78 \pm 0.1$
$102 \pm 3$
$4.5 \pm 0.2$
$101 \pm 2$
$0.84 \pm 0.01$
$>16$

NS
NS
NS
NS
NS
NS
0.03
0.0001

Data are presented as $n$ or mean + SEM, unless otherwise stated. FEV1: forced expiratory volume in $1 \mathrm{~s}$; FVC: forced vital capacity; PC20: provocative concentration of methacholine causing a $20 \%$ fall in FEV1; NS: not significant.

airway fibroblasts derived from subjects with asthma and from normal subjects at baseline, with no treatment, for collagen I and III (data not shown). IL-13 exposure significantly increased expression of COL1A2 (fold change between IL-13-treated compared to untreated fibroblasts $1.56 \pm 0.1$ in asthma compared to $0.808 \pm 0.23$ in normal subjects) ( $\mathrm{p}<0.05$ asthma versus normal subjects and within the asthma group) (fig. 1). However, there was no significant change in expression for COL1A1 or COL3A1 when comparing asthmatic subjects to normal subjects or within the asthma group (fig. 1).

Secondly, we treated these airway fibroblasts with a pan-MMP inhibitor in combination with IL-13 for $48 \mathrm{~h}$ to evaluate whether MMPs are necessary for IL-13-induced COL1A2 expression. This pan-MMP inhibitor blocks MMP-1, -2, -8 and -9. Our results demonstrate that the pan-MMP inhibitor significantly attenuated the IL-13-induced COL1A2 expression (fold change from IL-13 plus pan-MMP inhibitor to IL-13 treated fibroblasts $0.48 \pm 0.13$ within asthma compared to $0.93 \pm 0.13$ in normal subjects) $(\mathrm{p}<0.05$ comparing asthma versus normal controls and within the asthma group) (fig. 2).

Since MMP-2 is produced by fibroblasts and is presumably inhibited by the pan-MMP inhibitor, we next evaluated whether MMP-2 may be involved in our observed IL-13-induced COL1A2 expression in airway fibroblasts. Therefore, we co-treated airway fibroblasts with IL-13 and an inhibitor specific for MMP-2 for $48 \mathrm{~h}$. Once again, we found that COL1A2 expression was significantly attenuated after co-incubating the fibroblasts with both IL-13 and a specific MMP-2 inhibitor (fold change from fibroblasts treated with IL-13 plus MMP-2 inhibitor to IL-13 alone $0.38 \pm 0.11$ in asthma compared to $1.10 \pm 0.13$ in normal subjects) $(\mathrm{p}<0.01$ between asthma and normal subjects and within the asthma group) (fig. 2$)$. There was no significant effect on COL1A2 expression following exposure of the cells to specific MMP-1 or MMP-3

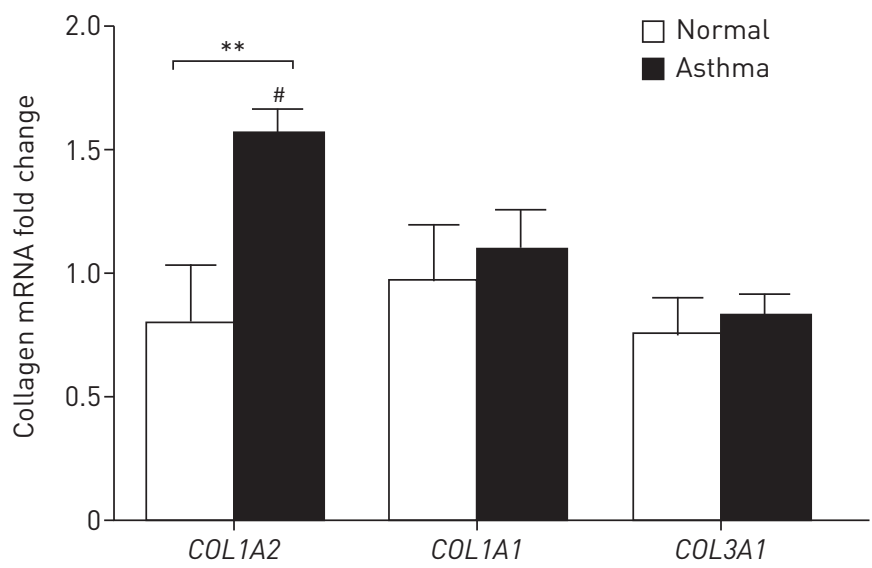

FIGURE 1 COL1A2 mRNA expression was significantly induced by interleukin-13 $\left(50 \mathrm{ng} \cdot \mathrm{mL}^{-1}\right)$ in asthma. COL1A2, COL1A1 and COL3A1 mRNA expression was measured by quantitative real-time reverse transcriptase-PCR in airway fibroblasts isolated from asthmatic $(n=15)$ and normal controls $(n=15)$. Data are presented as fold change from untreated fibroblasts. $^{* *}: \mathrm{p}<0.01$ between asthma and normal controls; ${ }^{*}: \mathrm{p}<0.01$ within asthmatic subjects. 


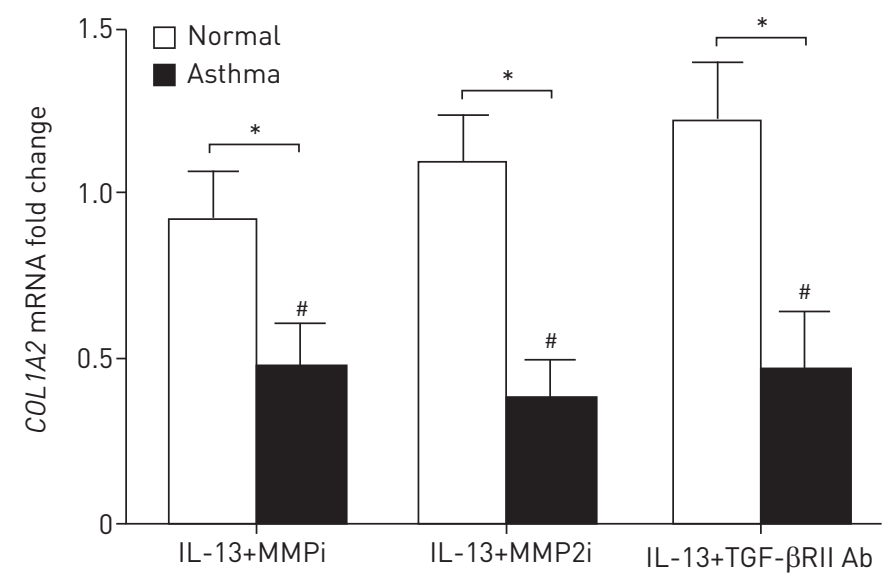

FIGURE 2 Significant attenuation in interleukin (IL)-13-induced COL1A2 mRNA expression was observed at $48 \mathrm{~h}$ when a matrix metalloproteinase (MMP) inhibitor $(\mathrm{MMPi})(10 \mu \mathrm{M})$, a specific MMP2 inhibitor (MMP2i) $(40 \mu \mathrm{M})$ and a transforming growth factor- $\beta$ receptor II (TGF- $\beta$ RII)-neutralising antibody $(\mathrm{Ab})\left(20 \mu \mathrm{g} \cdot \mathrm{mL}^{-1}\right)$ were added to IL-13treated airway fibroblasts in asthma subjects $(n=15)$ compared to normal subjects $(n=15)$ and within asthma patients alone as measured by real-time reverse transcriptase-PCR. Data are presented as fold change from fibroblasts from each group treated with IL-13 alone. ${ }^{*}: \mathrm{p}<0.05$ between asthma and normal subjects; ${ }^{*}: \mathrm{p}<0.05$ within the asthma group for each condition.

inhibitors (data not shown). Although MMP-9 was shown to be involved in murine models of airway remodelling, we did not evaluate its effects in this model since we were unable to detect any measurable MMP-9 expression in the airway fibroblasts in this study (data not shown).

To determine whether TGF- $\beta 1$ was involved in COL1A2 expression, we incubated airway fibroblasts with a TGF- $\beta$ RII neutralising antibody $\left(20 \mu \mathrm{g} \cdot \mathrm{mL}^{-1}\right)$ in combination with IL-13 $\left(50 \mathrm{ng} \cdot \mathrm{mL}^{-1}\right)$ for $48 \mathrm{~h}$. Using realtime reverse transcriptase PCR, our results show that COL1A2 mRNA expression was significantly attenuated when TGF- $\beta$ RII neutralising antibody was added to the airway fibroblast cultures in the presence of IL-13 (fold change from IL-13 plus TGF- $\beta$ RII antibody to IL-13-treated fibroblasts $0.47 \pm 0.17$ in asthma compared to $1.22 \pm 0.11$ in normal subjects) ( $<<0.05$ between asthma and normal subjects and within asthma) (fig. 2). This effect was not seen using a goat IgG control antibody (data not shown).

\section{Collagen protein expression by airway fibroblasts}

In order to evaluate whether gene expression correlated with increased collagen I protein expression, we used a commercial ELISA kit to quantify the amount of collagen protein in airway fibroblast cell culture supernatants. We incubated the fibroblasts with IL-13 for $48 \mathrm{~h}$ and compared the ratio of collagen protein expression to untreated fibroblasts for both asthma and normal subjects. Although group means at baseline were not statistically different, there was individual variability within each group (online supplementary fig. S1). Therefore, the data are presented as a ratio to untreated fibroblasts. The ratio of collagen in the IL13-treated fibroblasts as compared to the untreated fibroblasts was significantly elevated in asthma patients as compared to normal subjects (ratio of collagen protein in IL-13-treated to untreated fibroblasts $1.29 \pm 0.14$ in asthma compared to $0.88 \pm 0.12$ in controls) $(\mathrm{p}<0.05$ between asthma and normal subjects and within the asthma group) (fig. 3).

Next, we evaluated whether an MMP-2 inhibitor would have similar effects in attenuating the amount of collagen protein expression in airway fibroblast cell culture supernatants using the same ELISA. We found that treating airway fibroblasts with a MMP-2 inhibitor and IL-13 together resulted in a significant reduction in the amount of collagen protein as compared to those fibroblasts treated with IL-13 alone, particularly in asthma subjects as compared to normal subjects (ratio of collagen expression after exposure to IL-13 plus MMP-2 inhibitor relative to IL-13 alone for collagen protein $0.39 \pm 0.11$ in asthma compared to $0.97 \pm 0.04$ in controls) $(\mathrm{p}<0.05$ between asthma and normal subjects and within the asthma group) (fig. 3 )

\section{MMP-2 activation}

MMP-2 is an enzyme that is secreted as a pro-enzyme requiring activation in order to function. Using an MMP-2 activity assay, we evaluated whether IL-13 treatment resulted in increased MMP-2 activation. Our results show that IL-13 significantly activated MMP-2 in airway fibroblast cell culture supernatants from asthma subjects compared to normal subjects after treating airway fibroblasts with IL-13 for $48 \mathrm{~h}$ (ratio of MMP-2 activity in IL-13-treated fibroblasts as compared to untreated fibroblasts $1.20 \pm 0.08$ in 


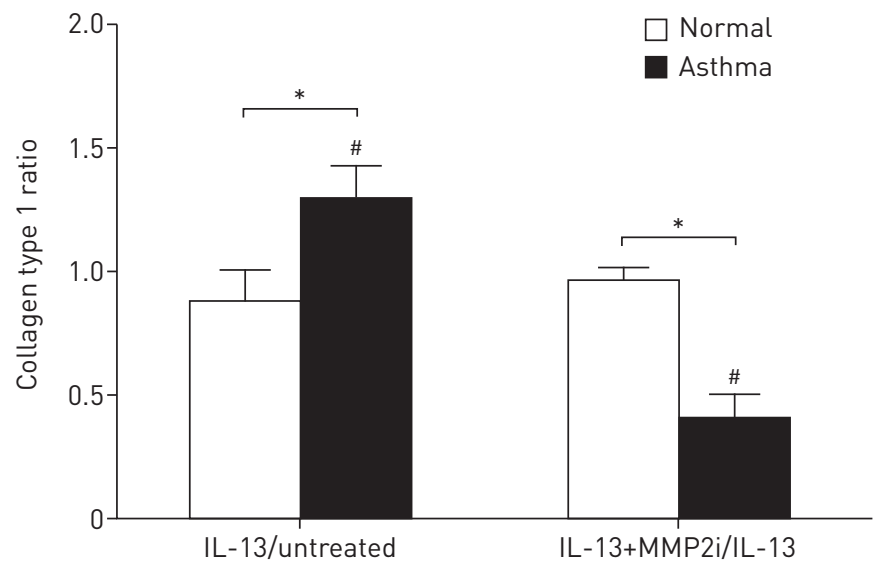

FIGURE 3 Collagen type-1 protein was induced by interleukin (IL)-13 $\left(50 \mathrm{ng} \cdot \mathrm{mL}^{-1}\right)$, depicted as the ratio of IL-13treated airway fibroblasts to untreated fibroblasts at $48 \mathrm{~h}$ in asthma $(\mathrm{n}=18)$ as compared to normal controls $(\mathrm{n}=12)$ and within asthma alone. Matrix metalloproteinase-2 inhibition (MMP2i) significantly attenuated IL-13-induced collagen type-1, depicted as the ratio of collagen type-I production following treatment with IL-13 plus MMP2i fibroblasts as compared to treatment with IL-13 alone, in asthma subjects as compared to normal subjects and within the asthma group. ${ }^{\star}: \mathrm{p}<0.05$ between asthma and normal controls; $: \mathrm{p}<0.05$ within asthmatic subjects for each condition.

asthma subjects compared to $0.76 \pm 0.09$ in normal subjects) ( $\mathrm{p}<0.05$ between asthma and normal subjects and within the asthma group) (fig. 4). Therefore, our results indicate that IL-13 is probably involved in activating MMP-2 in airway fibroblasts in asthma.

\section{TGF- $\beta 1$ expression and activation}

To determine whether IL-13 $\left(50 \mathrm{ng} \cdot \mathrm{mL}^{-1}\right)$ influenced both the total amount of TGF- $\beta 1$, as well as the endogenously active form of TGF- $\beta 1$, we incubated airway fibroblasts with IL- 13 at $50 \mathrm{ng} \cdot \mathrm{mL}^{-1}$ for $48 \mathrm{~h}$. Using a TGF- $\beta 1$ ELISA, we demonstrated that IL-13 significantly increased both total amount and the endogenously active form of TGF- $\beta 1$ versus untreated fibroblasts in asthma subjects as compared to normal subjects at $48 \mathrm{~h}$ (ratio of total TGF- $\beta 1$ from IL-13-treated fibroblasts to untreated fibroblasts $1.49 \pm 0.13$ in asthma compared to $0.67 \pm 0.26$ in normal subjects; ratio of active TGF- $\beta 1$ from IL- 13 -treated to untreated fibroblasts $1.30 \pm 0.15$ in asthma compared to $0.88 \pm 0.05$ in normal subjects) $(\mathrm{p}<0.05$ between asthma and normal controls and within the asthma group) (fig. $5 \mathrm{a}$ ).

To further confirm the potential of airway fibroblasts to produce bioactive TGF- $\beta 1$ in response to IL-13, we utilised mouse lung endothelial cells stably transfected with PAI-1-luciferase reporter to assay cell supernatants from cultures of airway fibroblasts from subjects with asthma or normal control subjects. Confluent airway fibroblasts were incubated with IL-13 $\left(50 \mathrm{ng} \cdot \mathrm{mL}^{-1}\right)$ or serum-free media for control for

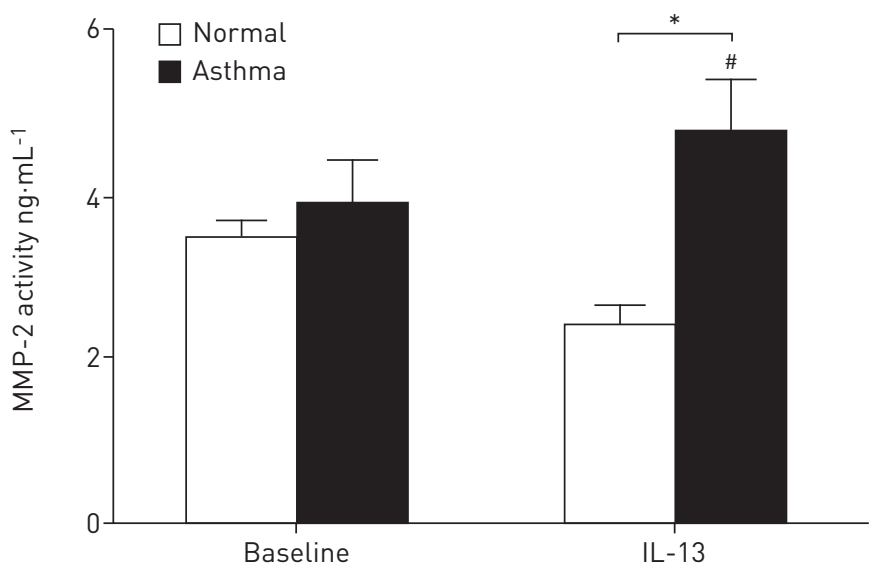

FIGURE 4 Matrix metalloproteinase (MMP)-2 activity in normal and asthmatic fibroblasts at baseline and after treatment with interleukin (IL)-13. MMP-2 activity is induced after treatment with IL-13 $\left(50 \mathrm{ng} \cdot \mathrm{mL}^{-1}\right)$ for $48 \mathrm{~h}$ in asthma $(\mathrm{n}=6)$ as compared to normal controls $(\mathrm{n}=4)$ and within asthma alone, as measured by an MMP-2 activation assay. ${ }^{*}$ : $\mathrm{p}<0.05$ between asthma and normal controls; ${ }^{*}: \mathrm{p}<0.05$ within asthmatic subjects for the IL-13 condition. 

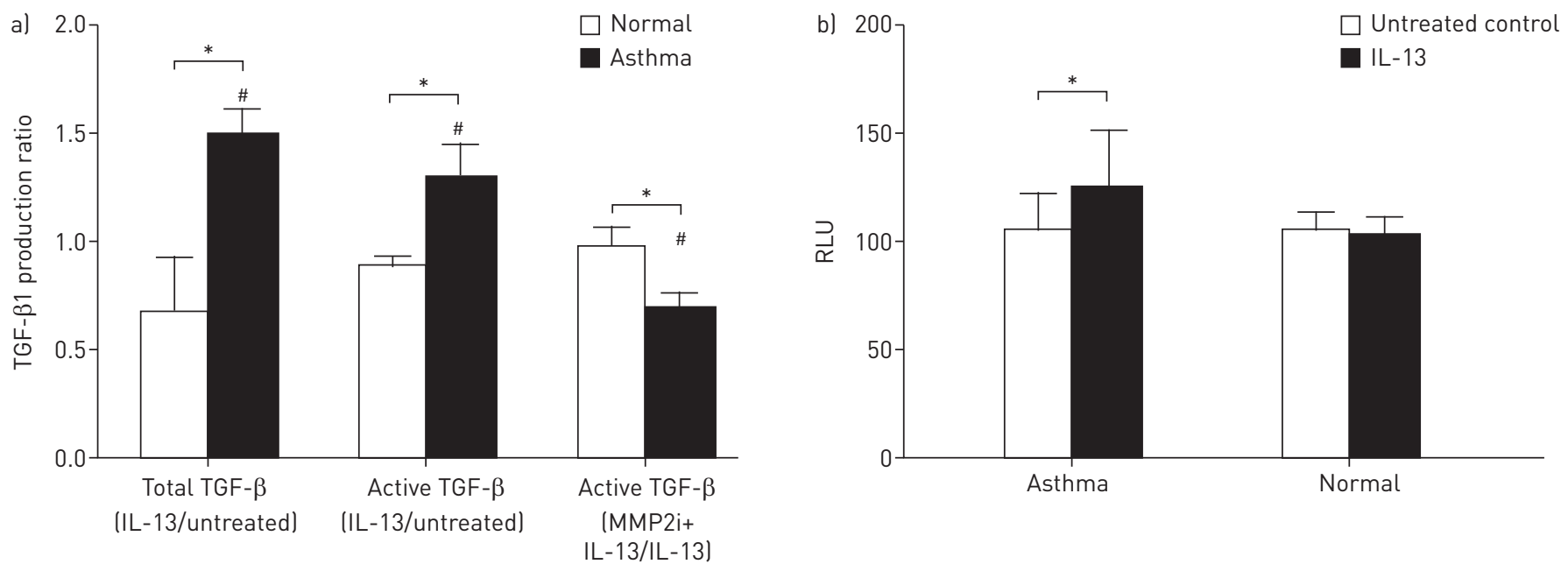

FIGURE 5 Interleukin (IL)-13 stimulates active transforming growth factor (TGF)- $\beta 1$ production by asthmatic airway fibroblasts. a) Total and endogenously active forms of TGF- $\beta 1$ from airway fibroblast cell culture supernatants were increased from baseline following stimulation with IL-13 (50 ng $\left.\cdot \mathrm{mL}^{-1}\right)$ at $48 \mathrm{~h}$ in asthma subjects $(n=9)$ as compared to normal subjects $(n=7)$ and within the asthma group, depicted as the ratio of TGF- $\beta 1$ production in fibroblasts treated with IL-13 as compared to untreated fibroblasts. Matrix metalloproteinase- 2 inhibition (MMP2i) blocked TGF- $\beta 1$ activation in fibroblasts treated with IL-13 in asthma subjects compared to normal subjects and within the asthma group, depicted as the ratio of TGF- $\beta 1$ activation after treatment with IL-13 plus MMP2i as compared to treatment with IL-13 alone (IL-13 plus MMP2i/IL-13). b) Bioactive TGF- $\beta 1$ levels, as represented by luciferase activity in airway fibroblast cell culture supernatants, were elevated following exposure to IL-13 $\left(50 \mathrm{ng} \cdot \mathrm{mL}^{-1}\right)$ at $48 \mathrm{~h}$ in asthma subjects $(\mathrm{n}=9)$ as compared to untreated controls. RLU: relative luciferase units. ${ }^{*}: \mathrm{p}<0.05$ between asthma and normal subjects; ${ }^{*}: \mathrm{p}<0.05$ within asthmatic subjects for each condition.

$48 \mathrm{~h}$, and the cell supernatants were assayed for luciferase production. IL-13 stimulated significantly increased levels of bioactive TGF- $\beta 1$, represented by relative luciferase units, in airway fibroblasts in asthma as compared to untreated control fibroblasts $(124.88 \pm 26.6 \mathrm{RLU}$ for IL-13-treated fibroblasts compared to 105.94 \pm 16.7 RLU for untreated control fibroblasts) ( $\mathrm{p}=0.04$ within the asthma group). No effect of IL-13 was observed in airway fibroblasts isolated from normal control subjects (103.14 \pm 8.0 RLU for IL-13treated fibroblasts compared to $106.71 \pm 6.0 \mathrm{RLU}$ for untreated control cells) (fig. 5b).

Furthermore, to determine whether MMP-2 may be responsible for activating TGF- $\beta 1$, we incubated airway fibroblasts with a specific MMP-2 inhibitor in combination with IL-13 and found that MMP-2 inhibition attenuated the activation of TGF- $\beta 1$ in asthma subjects compared to normal subjects at $48 \mathrm{~h}$ (ratio of active TGF- $\beta 1$ from IL-13-treated to untreated fibroblasts $0.69 \pm 0.07$ in asthma subjects compared to $0.99 \pm 0.08$ in normal subjects) $(\mathrm{p}<0.05$ between asthma and normal subjects and within the asthma group) (fig. $5 \mathrm{a})$.

\section{Expression of $\alpha$-SMA}

Using immunoblotting (fig. 6a) of cell culture lysates treated with IL-13 (50 ng. $\mathrm{mL}^{-1}$ ), we found that IL-13 increased protein production of both $\alpha$-SMA and desmin, two markers of myofibroblast phenotype, in asthmatic airway fibroblasts compared to untreated fibroblasts. No increase in production of $\alpha$-SMA or desmin was observed in airway fibroblasts isolated from normal control subjects. Densitometry analysis indicated a significant increase in IL-13-induced $\alpha$-SMA production by airway fibroblasts in asthma compared to normal controls (ratio of $\alpha$-SMA in IL-13-treated fibroblasts compared to untreated fibroblasts $1.96 \pm 0.42$ in asthma subjects compared to $0.91 \pm 0.07$ in normal subjects) $(\mathrm{p}=0.03$ between asthma subjects and normal subjects) (fig. 6b).

\section{Discussion}

In this study, we present evidence that IL-13 induces COL1A2 gene expression by bronchial fibroblasts in subjects with mild asthma compared to healthy control subjects. Interestingly, IL-13 had no effect on COL1A1 expression or COL3A1 expression. In addition, we show that IL-13 increases the amount of secreted mature type-1 collagen protein in the cell culture supernatants from airway fibroblasts derived from asthma patients. The assay used in our study does not discriminate between COL1A1 and COL1A2 and reflects total amount of collagen protein present.

Normal collagen protein is composed of two $\alpha 1$ chains and one $\alpha 2$ chain [27]. These data suggest that enhanced collagen production may be controlled through expression of COL1A2 exclusively or that a different mediator is responsible for inducing COL1A1 expression. Alternatively, COL1A1 may be 
a) Normal
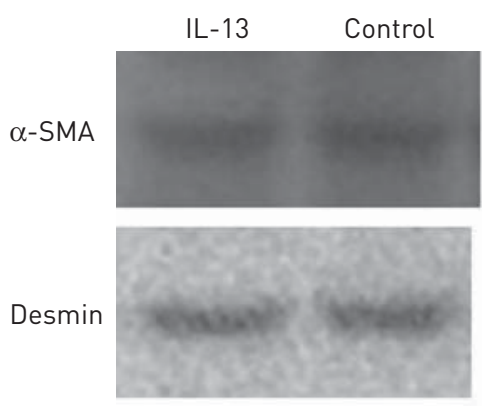

GAPDH

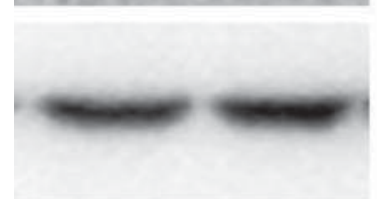

Asthma

IL-13 Control

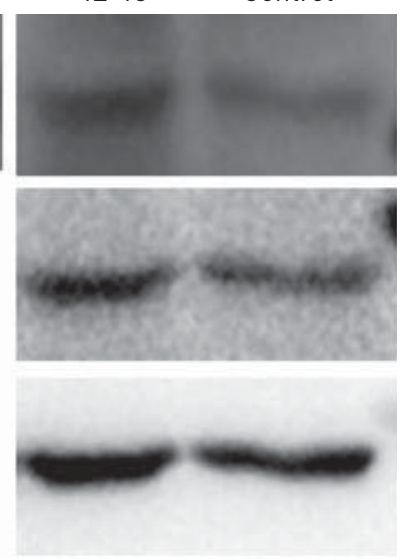

b)

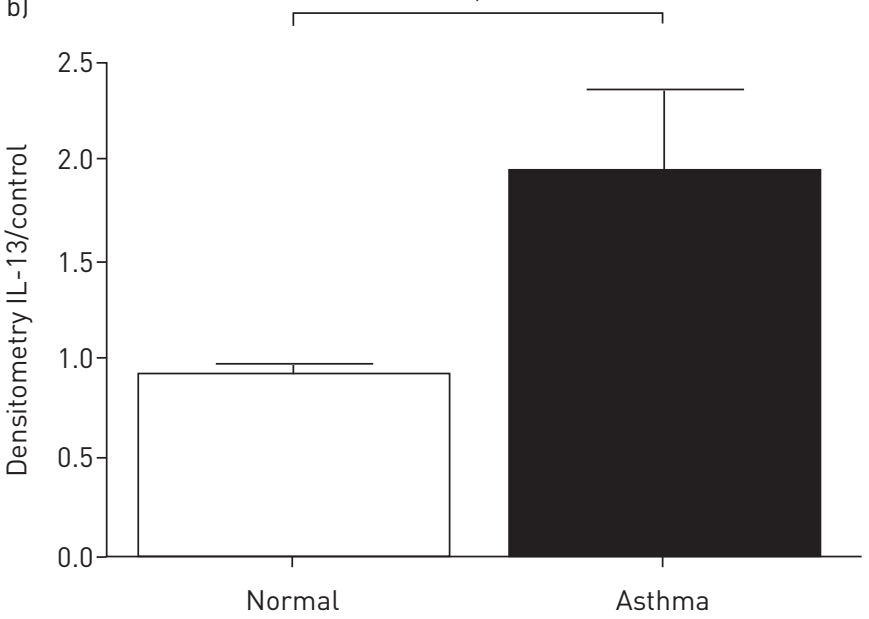

FIGURE 6 Expression of $\alpha$-smooth muscle actin (SMA) and desmin proteins in cell culture lysates from airway fibroblasts was increased in asthma patients following treatment with interleukin (IL)-13. Cell lysates were prepared from airway fibroblasts from either asthmatic or normal subjects after exposure to IL-13 $\left(50 \mathrm{ng} \cdot \mathrm{mL}^{-1}\right.$ ) or serum-free media (untreated control) for $48 \mathrm{~h}$. a) Representative Western blot of myofibroblast markers in airway fibroblasts in asthma or normal subjects. Expression of glyceraldehyde-3-phosphate dehydrogenase (GAPDH) indicates loading control. b) Quantification of data shown in a): mean \pm SEM of six asthma subjects and four normal controls. Data are expressed as the ratio of the intensity of bands following IL-13 to untreated control. ${ }^{*}: \mathrm{p}<0.05$ between asthma and normal subjects.

constitutively expressed and control of collagen production may be through COL1A2. However, in a study by Plante et al. [28] it was demonstrated that IL-4, another major Th2 cytokine, significantly induced COL1A1 gene expression. The authors did not analyse COL1A2 expression.

The mechanism by which IL-13 may promote airway fibrosis is largely unknown, although work in murine models suggests that it probably functions through activating TGF- $\beta 1$ in a MMP-dependent manner $[14,29]$. To test this effect, we wanted to examine the primary MMPs that have been associated with asthma including MMP-1, MMP-2, MMP-3 and MMP-9 [30]. In our study, we were unable to detect gene expression of MMP-9 in airway fibroblasts (data not shown), and therefore we did not study its effect using our experimental model. In our results, only MMP-2 inhibition was found to have a significant effect on reducing IL-13 induced collagen type-1 production in airway fibroblasts. Furthermore, we demonstrate that IL-13 significantly increased MMP2 activation in asthmatic airway fibroblasts compared to normal controls. The effects of IL-13 are mediated by its receptor subunits: IL-13R $\alpha 1$, IL$13 R \alpha 2$ and IL-4R $\alpha$. Previous work from our laboratory has shown that airway fibroblast cell surface expression of IL-13R $\alpha 2$ in asthma is suppressed compared with expression on airway fibroblasts from normal control subjects, while IL-13R $\alpha 1$ and IL- $4 \mathrm{R} \alpha$ were not significantly changed [31]. IL-13R $\alpha 2$ is thought to act as a decoy receptor to negatively regulate IL-13 signalling, and therefore its relative deficiency may explain enhanced airway fibroblast responsiveness to IL-13 [32]. TGF- $\beta 1$ is one of the most studied pro-fibrotic cytokines [33]. The potent activity of TGF- $\beta 1$ is regulated at the posttranscriptional level by a latency-associated protein (LAP), which keeps TGF- $\beta 1$ in an inactive state. Dissociation of TGF- $\beta 1$ from LAP is required to release biologically active TGF- $\beta 1$. In our experiments, we demonstrate that IL-13 increases both the total amount as well as the activated form of TGF- $\beta 1$ in cell culture supernatants from airway fibroblasts in asthma patients at $48 \mathrm{~h}$ using both ELISA and a functional bioassay specific for the active form of TGF- $\beta 1$. One of the potential roles for MMP- 2 may be to trigger release of TGF- $\beta 1$, a well-known mediator in fibrosis, from its LAP allowing it to stimulate fibrosis [33]. This mechanism has been previously shown to occur with MMP-9 as well as other agents such as plasmin $[29,34]$. We show that activation of TGF- $\beta 1$ was attenuated following treatment with a specific MMP-2 inhibitor. Once activated, TGF- $\beta 1$ binds primarily to TGF- $\beta$ RII, which then recruits the type-I receptor for downstream signalling [35]. TGF- $\beta 1$ has also been shown to augment IL-13 signalling by dampening expression of IL-13R $\alpha 2$ [36]. This would potentially allow fibroblasts to overcome the autoregulatory pathway of IL-13 and remain in a state of persistent responsiveness to IL13. To further study the effects of TGF- $\beta 1$ in this pathway, the addition of a TGF- $\beta$ RII-neutralising antibody significantly decreased the IL-13-induced expression of COL1A2, also suggesting that TGF- $\beta 1$ is involved in this pathway downstream of IL-13. One of the mechanisms by which IL-13 may lead to increased collagen deposition is through changing the phenotype of normal airway fibroblasts to the more synthetic myofibroblast. As we demonstrate qualitatively in our experiments, IL-13 induced 
expression of both $\alpha$-SMA and desmin, two known markers for myofibroblasts, in our asthmatic airway fibroblasts. In our previous work, we have shown that IL-13 potentiates airway fibroblast invasion in asthma subjects, a feature associated with myofibroblast differentiation, through a mechanism involving TGF- $\beta 1$. Other investigators have also implicated TGF- $\beta 1$ as a critical mediator of myofibroblast differentiation and activation [37, 38]. The increased expression of $\alpha$-SMA and desmin suggests that the airway fibroblasts in asthma subjects in response to IL-13 change their phenotype to myofibroblasts, although this mechanism requires further investigation.

Limitations of our study include evaluation of mediators only relevant to airway fibroblasts, and clearly other cells and their products are involved in airway remodelling. In addition, all of our findings were based on mildly asthmatic patients who may behave differently, or have reduced remodelling signals as compared to patients with more severe asthma. In addition, we studied fibroblasts isolated from proximal airways, which may not behave in the same fashion as distal airway fibroblasts.

Our study demonstrates that IL-13 induces collagen type-1 production in airway fibroblasts cultured directly from mild asthmatic patients compared to healthy controls. We also show that IL-13 likely induces collagen production in an MMP-2-dependent manner, which is a novel finding in human asthma. We show that MMP-2 probably induces collagen production by activating latent TGF- $\beta 1$, and this mechanism may be a major contributor to the pathogenesis of airway fibrosis seen in this disease. There have been recent advances in the development of therapeutic monoclonal antibodies directed against IL-13 in poorly controlled asthma. Two recent studies found that using IL-13 monoclonal antibodies improved airway function in these patients $[39,40]$. While this is an exciting development in an area that desperately needs better therapies to treat severe asthma, our findings also provide some insight that interventions leading to a decrease in IL-13-induced TGF- $\beta 1$ activation could be beneficial in reducing airway remodelling in asthmatic patients. The use of such an IL-13 inhibitor or a therapeutic MMP-2 inhibitor may achieve this goal and provide a starting point for further study. Thus, there may be therapeutic options available for a process that to date has had none, particularly in the patients with more severe asthma.

\section{References}

Wynn TA. IL-13 effector functions. Annu Rev Immunol 2003; 21: 425-456.

Elias JA, Zhu Z, Chupp G, et al. Airway remodeling in asthma. J Clin Invest 1999; 104: 1001-1006.

James AL, Wenzel S. Clinical relevance of airway remodelling in airway diseases. Eur Respir J 2007; 30: 134-155.

Bumbacea D, Campbell D, Nguyen L, et al. Parameters associated with persistent airflow obstruction in chronic severe asthma. Eur Respir J 2004; 24: 122-128.

Roche WR, Williams JH, Beasley R, et al. Subepithelial fibrosis in the bronchi of asthmatics. Lancet 1989; 333 : 520-524.

6 Chakir J, Laviolette M, Boutet M, et al. Lower airways remodeling in nonasthmatic subjects with allergic rhinitis. Lab Invest 1996; 75: 735-744.

7 Brewster CE, Howarth PH, Djukanovic R, et al. Myofibroblasts and subepithelial fibrosis in bronchial asthma. Am J Respir Cell Mol Biol 1990; 3: 507-511.

8 Kelly EA, Jarjour NN. Role of matrix metalloproteinases in asthma. Curr Opin Pulm Med 2003; 9: 28-33.

Ohbayashi H. Matrix metalloproteinases in lung diseases. Curr Protein Pept Sci 2002; 3: 409-421.

10 Zheng T, Zhu Z, Wang Z, et al. Inducible targeting of IL-13 to the adult lung causes matrix metalloproteinase- and cathepsin-dependent emphysema. J Clin Invest 2000; 106: 1081-1093.

11 Lee CG, Kang HR, Homer RJ, et al. Transgenic modeling of transforming growth factor- $\beta_{1}$ : role of apoptosis in fibrosis and alveolar remodeling. Proc Am Thorac Soc 2006; 3: 418-423.

12 Ohno I, Nitta Y, Yamauchi K, et al. Transforming growth factor $\beta 1$ (TGF $\beta 1$ ) gene expression by eosinophils in asthmatic airway inflammation. Am J Respir Cell Mol Biol 1996; 15: 404-409.

13 Lee CG, Cho SJ, Kang MJ, et al. Early growth response gene 1-mediated apoptosis is essential for transforming growth factor $\beta_{1}$-induced pulmonary fibrosis. J Exp Med 2004; 200: 377-389.

14 Lee CG, Homer RJ, Zhu Z, et al. Interleukin-13 induces tissue fibrosis by selectively stimulating and activating transforming growth factor $\beta_{1}$. J Exp Med 2001; 194: 809-821.

15 Fulkerson PC, Fischetti CA, Hassman LM, et al. Persistent effects induced by IL-13 in the lung. Am J Respir Cell Mol Biol 2006; 35: 337-346.

16 Fichtner-Feigl S, Strober W, Kawakami K, et al. IL-13 signaling through the IL-13 $\alpha_{2}$ receptor is involved in induction of TGF- $\beta_{1}$ production and fibrosis. Nat Med 2006; 12: 99-106.

17 Fichtner-Feigl S, Young CA, Kitani A, et al. IL-13 signaling via IL-13R $\alpha_{2}$ induces major downstream fibrogenic factors mediating fibrosis in chronic TNBS colitis. Gastroenterology 2008; 135: 2003-2013.

18 Zuo L, Fulkerson PC, Finkelman FD, et al. IL-13 induces esophageal remodeling and gene expression by an eosinophil-independent, IL-13R $\alpha 2$-inhibited pathway. J Immunol 2010; 185: 660-669.

19 American Thoracic Society. Standards for the diagnosis and care of patients with chronic obstructive pulmonary disease (COPD) and asthma. This official statement of the American Thoracic Society was adopted by the ATS Board of Directors, November 1986. Am Rev Respir Dis 1987; 136: 225-244.

20 Pham DN, Chu HW, Martin RJ, et al. Increased matrix metalloproteinase-9 with elastolysis in nocturnal asthma. Ann Allergy Asthma Immunol 2003; 90: 72-78.

21 Kraft M, Lewis C, Pham D, et al. IL-4, IL-13, and dexamethasone augment fibroblast proliferation in asthma. J Allergy Clin Immunol 2001; 107: 602-606. 
fibroblasts from normal and asthmatic subjects. Lab Invest 1998; 78: 297-307.

23 Voynow JA, Fischer BM, Malarkey DE, et al. Neutrophil elastase induces mucus cell metaplasia in mouse lung. Am J Physiol Lung Cell Mol Physiol 2004; 287: L1293-L1302.

24 Abe M, Harpel JG, Metz CN, et al. An assay for transforming growth factor- $\beta$ using cells transfected with a plasminogen activator inhibitor-1 promoter-luciferase construct. Anal Biochem 1994; 216: $276-284$.

25 Mukherjee S, Giamberardino C, Thomas JM, et al. Surfactant protein A modulates induction of regulatory T cells via TGF- $\beta$. J Immunol 2012; 188: 4376-4384.

26 National Asthma Education and Prevention Program. Expert Panel Report 3 (EPR-3): guidelines for the diagnosis and management of asthma - summary report 2007. J Allergy Clin Immunol 2007; 120: Suppl. 5, S94-S138.

27 Last JA, Reiser KM. Collagen biosynthesis. Environ Health Perspect 1984; 55: 169-177.

28 Plante S, Semlali A, Joubert P, et al. Mast cells regulate procollagen I $\left(\alpha_{1}\right)$ production by bronchial fibroblasts

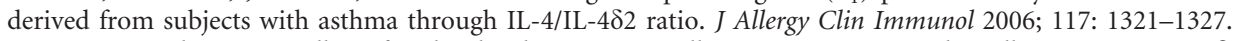

$29 \mathrm{Yu}$ Q, Stamenkovic I. Cell surface-localized matrix metalloproteinase-9 proteolytically activates TGF- $\beta$ and promotes tumor invasion and angiogenesis. Genes Dev 2000; 14: 163-176.

30 Demedts IK, Brusselle GG, Bracke KR, et al. Matrix metalloproteinases in asthma and COPD. Curr Opin Pharmacol 2005; 5: 257-263.

31 Ingram JL, Huggins MJ, Church TD, et al. Airway fibroblasts in asthma manifest an invasive phenotype. Am J Respir Crit Care Med 2011; 183: 1625-1632.

32 Mentink-Kane MM, Wynn TA. Opposing roles for IL-13 and IL-13 receptor $\alpha 2$ in health and disease. Immunol Rev 2004; 202: 191-202.

33 Malavia NK, Mih JD, Raub CB, et al. IL-13 induces a bronchial epithelial phenotype that is profibrotic. Respir Res 2008; 9: 27.

34 Khalil N, Corne S, Whitman C, et al. Plasmin regulates the activation of cell-associated latent TGF- $\beta 1$ secreted by rat alveolar macrophages after in vivo bleomycin injury. Am J Respir Cell Mol Biol 1996; 15: 252-259.

35 Boxall C, Holgate ST, Davies DE. The contribution of transforming growth factor- $\beta$ and epidermal growth factor signalling to airway remodelling in chronic asthma. Eur Respir J 2006; 27: 208-229.

36 Zhou X, Hu H, Balzar S, et al. MAPK regulation of IL-4/IL-13 receptors contributes to the synergistic increase in CCL11/eotaxin-1 in response to TGF- $\beta 1$ and IL-13 in human airway fibroblasts. J Immunol 2012; 188 : 6046-6054.

37 Petrov VV, Fagard RH, Lijnen PJ. Stimulation of collagen production by transforming growth factor- $\beta_{1}$ during differentiation of cardiac fibroblasts to myofibroblasts. Hypertension 2002; 39: 258-263.

38 Casey TM, Eneman J, Crocker A, et al. Cancer associated fibroblasts stimulated by transforming growth factor $\beta 1$ (TGF- $\beta 1$ ) increase invasion rate of tumor cells: a population study. Breast Cancer Res Treat 2008; 110: 39-49.

39 Corren J, Lemanske RF, Hanania NA, et al. Lebrikizumab treatment in adults with asthma. N Engl J Med 2011; 365: 1088-1098.

40 Piper E, Brightling C, Niven R, et al. A phase II placebo-controlled study of tralokinumab in moderate-to-severe asthma. Eur Respir J 2013; 41: 330-338. 